\title{
PENENTUAN AWAL WAKTU SHALAT
}

Oleh: A. Frangky Soleiman

\begin{abstract}
ABSTRAK
Awal waktu shalat merupakan perhitungan yang ditetapkan dengan berdasarkan garis edar matahari atau penelitian posisi matahari terhadap bumi, oleh karena itu menghitung awal waktu shalat adalah menghitung kapan matahari akan menempati posisi tertentu yang sekaligus menjadi penunjuk waktu shalat, yaitu pada saat tergelincir, saat membuat bayang-bayang sama panjang dengan bendanya, saat terbenam, saat hilangnya mega merah, saat terbitnya fajar dan saat terbitnya matahari.
\end{abstract}

Kata kunci: Waktu Shalat

\section{A. PENDAHULUAN}

Waktu merupakan masalah yang krusial dalam Islam, ini tertuang dalam al-Qur'an surat al-Syams ayat $1-6$, al-Fajr 1 - 4 dan surat al-lail, dan didalam satu surah yang lain yaitu surah al-Ashr (103) : 1 - 3 yang mengatakan :

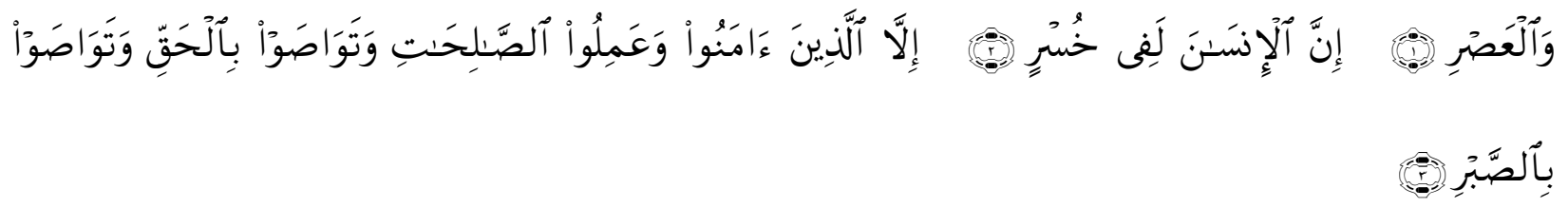

"Demi masa, Sesungguhnya manusia itu benar-benar dalam kerugian, Kecuali orang-orang yang beriman dan mengerjakan amal saleh dan nasehat menasehati supaya mentaati kebenaran dan nasehat menasehati supaya menetapi kesabaran."

Dari beberapa surah yang disebutkan tadi pokok intinya adalah tentang waktu yang berkaitan dengan ibadah (salat), karena salat merupakan salah satu rukun Islam yang yang ditegakkan oleh orang-orang yang beriman pada waktu-waktu yang ditentukan (QS. anNisa (4): 103) yaitu : 


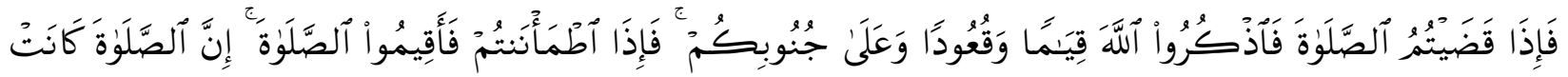

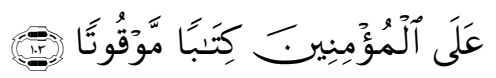

"Maka apabila kamu telah menyelesaikan shalat(mu), ingatlah Allah di waktu berdiri, di waktu duduk dan di waktu berbaring. kemudian apabila kamu telah merasa aman, Maka dirikanlah shalat itu (sebagaimana biasa). Sesungguhnya shalat itu adalah fardhu yang ditentukan waktunya atas orang-orang yang beriman".

Al-Qur'an mengajarkan untuk memanfaatkan waktu karena waktu adalah ibadah. Ibadah dalam hubungan ini, adalah posisi matahari untuk penentuan awal dan akhir salat sangat penting, mengingat petunjuk pelaksanaan beberapa ayat al-Qur'an dan hadis semata-mata isyarat saja yaitu hanya berdasar atas keadaan perjalanan matahari setempat dimana kita berada. ${ }^{1}$ Menurut Muhyiddin Khazin waktu-waktu salat yang ditunjukkan oleh al-Qur'an maupun hadis Nabi hanya berupa fenomena alam, yang kalu tidak mengguankan ilmu falak, tentunya akan mengalami kesulitan dalam menentukan awal waktu salat. Untuk menentukan awal waktu zuhur misalnya, kita harus keluar rumah melihat matahari berkulminasi. Demikian pula untuk menentukan awal waktu ashar kita harus keluar rumah dengan membawa tongkat kemudian mengukur dan membandingkan dengan panjang bayangan tongkat itu, dan seterusnya ${ }^{2}$

Karena perjalanan semu matahari itu relative tetap, maka waktu posisi matahari pada awal waktu-waktu salat setiap hari sepanjang tahun mudah dapat diperhitungkan. Dengan demikian orang yang akan melakukan salat pada awal waktunya menemui kemudahan.

\section{B. PEMBAHASAN}

Penentuan awal waktu salat merupakan bagian dari ilmu falak yang perhitungannya ditetapkan berdasarkan garis edar matahari atau penelitian posisi matahari terhadap bumi. Oleh karena itu, menghisab waktu salat pada dasarnya adalah menghitung kapan matahari

\footnotetext{
${ }^{1}$ Ali Parman, Ilmu Falak, (Cet. I : Makassar : 2001), h. 23

${ }^{2}$ Muhyiddin Khazin, IImu Falak dan Teori dan praktiknya, (Cet. I; Yogjakarta: 2004), h. 81
} 
akan menempati posisi tertentu yang sekaligus menjadi penunjuk waktu salat, yatu pada saat tergelincir, saat membuat bayang-bayang sama panjang dengan bendanya, saat terbenam, saat hilangnya mega merah, saat terbitnya fajar dan saat terbit. Sehubungan dengan itu, saat matahari berkulminasi (mencapai titik puncak) seringkali juga dijadikan pedoman dalam menghisab setiap awal atau akhir waktu salat. Begitu juga dengan persoalan berapa lama waktu yang diperlukan oleh matahari untuk bergerak dari titik kulminasi sampai kepada posisi awal atau akhir waktu salat yang dicari.

Dalam hadits yang diriwayatkan oleh Ahmad, an-Nasa'i dan Turmudzi dari Jabir bin Abdullah ra. Mengatakan ${ }^{3}$ :

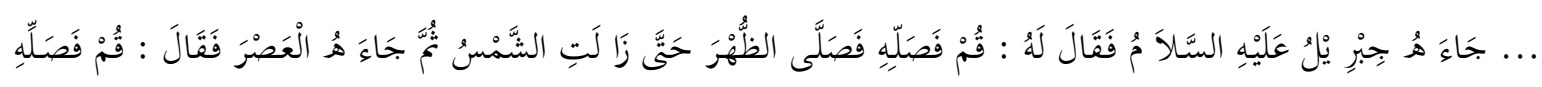

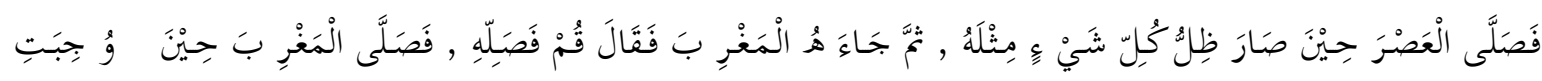

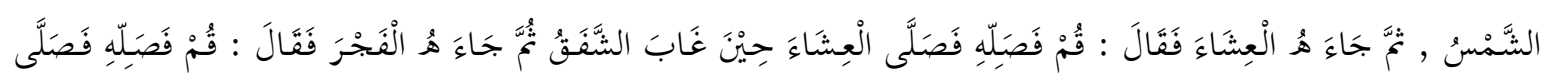

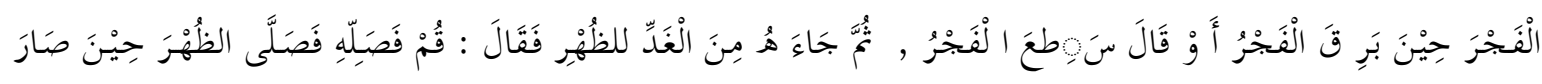

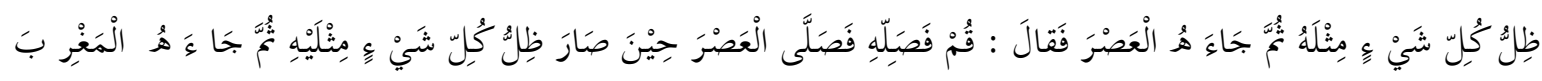

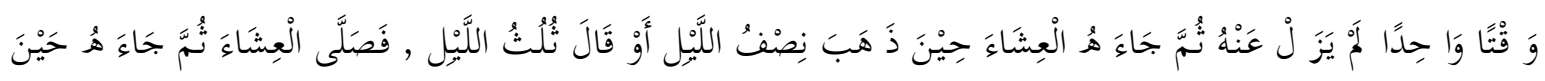

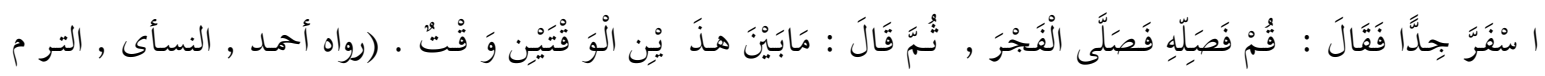

\section{Terjemahannya:}

"Telah datang kepada Nabi Muhammad saw Jibril as lalu berkata kepadanya: bangunlah! lalu salatlah, kemudian Nabi saw salat Dzuhur di kala matahari tergelincir, kemudian datang lagi ia di lain waktu kepada Nabi saw di waktu Ashar lalu berkata: bangunlah lalu salatlah, kemudian Nabi saw salat Ashar di kala bayangbayang sesuatu sama dengan panjang bendanya, kemudian ia datang lagi diwaktu Maghrib lalu berkata: bangunlah lalu salatlah, kemudian Nabi saw salat Maghrib

\footnotetext{
${ }^{3}$ Encip Supriatna, Hisab Rukyah dan Aplikasinya, (Cet.l; PT. Refika Aditama: Bandung), h. 17 -18
} 
dikala matahari terbenam, kemudian dilain waktu ia datang di waktu Isya' lalu berkata: bangunlah lalu salatlah, kemudian Nabi saw salat Isya di kala mega merah di ufuk Barat telah terbenam, kemudian ia datang lagi diwaktu fajar lalu berkata: bangunlah lalu salatlah, kemudian Nabi saw salat Fajar (Shubuh) di kala fajar menyingsing atau diwaktu fajar bersinar, kemudian Jibril as datang lagi pada hari lain di waktu Dzuhur, lalu berkata kepada Nabi saw: bangunlah lalu salatlah, kemudian Nabi saw salat Dzuhur di kala bayang-bayang sesuatu benda sama dengan panjangnya, kemudian datang lagi diwaktu Ashar dan berkata: bangunlah lalu salatlah, kemudian Nabi saw salat Ashar di kala bayang-bayang suatu benda dua kali panjang benda itu, kemudian ia datang lagi diwaktu Maghrib dalam waktu yang sama dan tidak bergeser dari waktu yang semula sebagaimana sebelumnya, kemudian ia datang lagi kepada Nabi saw diwaktu Isya' di kala telah berlalu separuh malam, atau telah hilang sepertiga malam, kemudian Nabi saw salat Isya', selanjutnya ia datang lagi kepada Nabi saw di kala telah muncul cahaya benar (terang) di ufuk Timur dari sinar matahari yang sebentar lagi terbit lalu berkata: bangunlah lalu salatlah, kemudian Nabi saw salat fajar (Shubuh), kemudian Jibril as berkata kepada Nabi Muhammad saw: bahwa saat atau waktu-waktu di antara dua waktu tersebut di atas adalah batas awal dan akhir dari waktu-waktu salat fardhu."

Berdasarkan pada hadits di atas, maka kita bisa menetapkan waktu-waktu salat, yang pada intinya adalah sbb :

1. Waktu Zuhur : dimulai sejak matahari tergelincir, yaitu sesaat setelah matahari mencapai titik kulminasi (puncak) dalam peredaraan hariannya, sampai tiba waktu ashar. Dalam dalam hadis diterangkan bahwa Nabi salat zuhur ketika matahari tergelincir dan disebutkan pula ketika bayang-bayang sama panjang dengan dirinya. Ini tidaklah bertentangan sabab untuk Saudi Arabaia yang berlintang sekitar $20^{\circ}-30^{\circ}$ utara pada saat matahari tergelincir panjang bayang-bayang dapat menapai panjang bendanya bahkan lebih. Keadaan ini dapat terjadi ketika matahari sedang berposisi jauh di selatan, yakni di antara bulan juni dan Desember. ${ }^{4}$

Jika matahari sedang berkulminasi, maka titik pusat matahari berkedudukan tepat di meridian. Dalam keadaan yang demikian, jika matahari tidak berkulminasi di zenith, bayang-bayang sebuah benda yang terpancang tegak lurus di atas tanah, membujur

\footnotetext{
${ }^{4}$ Ibid, h. 19
} 
tepat Menurut arah Utara - Selatan. Garis poros bayang-bayang itu dan titik pusat matahari membentuk sebuah bidang, yang berimpitan dengan bidang meridian. ${ }^{5}$ Segera setelah titik pusat matahari dalam perjalanan matahari arah ke Barat, melepaskan diri dari garis meridian, maka ujung bayang-bayang benda yang dimaksud tadi, akan melepaskan diri pula dari garis Utara - Seletan dan bergerak ke sebelah timur, bidang yang dibuat oleh poros bayang-bayang dan titik pusat matahari, sekarang membentuk sudut dengan bidang meridian, kedua bidang itu berpotong-potongan pada garis vertical tempat. Kedaan demikian disebutkan sebagai “ tergelincir"nya matahari, yaitu awal waktu zhuhur. Dengan jalan demikian, maka secara ilmu pasti, waktu berkulminasi matahari dapat ditetapkan sebagai batas permulaan waktu zuhur. ${ }^{6}$

Untuk itu maka lebih lanjut Muhyiddin Khazin mengatakan bahwa, Sebelum melakukan perhitungan awal waktu-waktu shalat, ada baiknya mengetahui tiga istilah, yaitu Tinggi Matahari, Sudut Waktu Matahari, dan Ikhtiyat ${ }^{7}$

\section{a. Tinggi Matahari}

Tinggi Matahari adalah jarak busur sepanjang lingkaran vertikal dihitung dari ufuk sampai matahari. Dalam ilmu falak disebut Irtifa'us Syams yang biasa diberi notasi $\mathbf{h}_{\mathbf{o}}$ (hight of Sun).

Tinggi matahari bertanda positif (+) apabila posisi matahari berada di atas ufuk. Demikian pula bertanda negatif (-) apabila matahari di bawah ufuk.

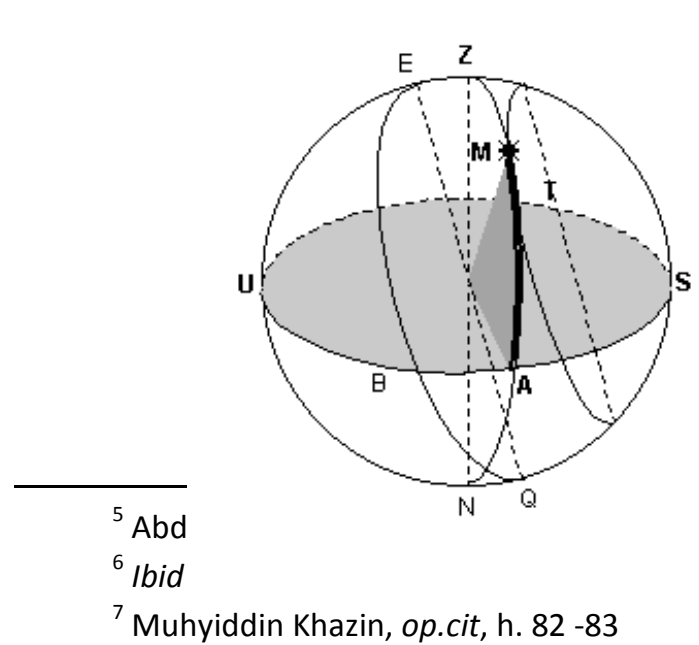

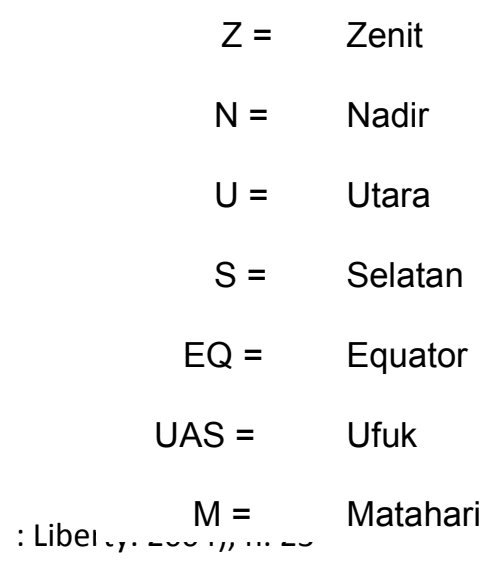




\section{b. Sudut Waktu Matahari ${ }^{8}$}

Sudut Waktu Matahari adalah busur sepanjang lingkaran harian matahari dihitung dari titik kulminasi atas sampai matahari berada. Atau sudut pada kutub langit selatan atau utara yang diapit oleh garis meridian dan lingkaran deklinasi yang melewati matahari. Dalam ilmu falak disebut Fadl-lud Da'ir yang biasa dilambangkan dengan $\mathbf{t}_{\mathbf{0}}$.
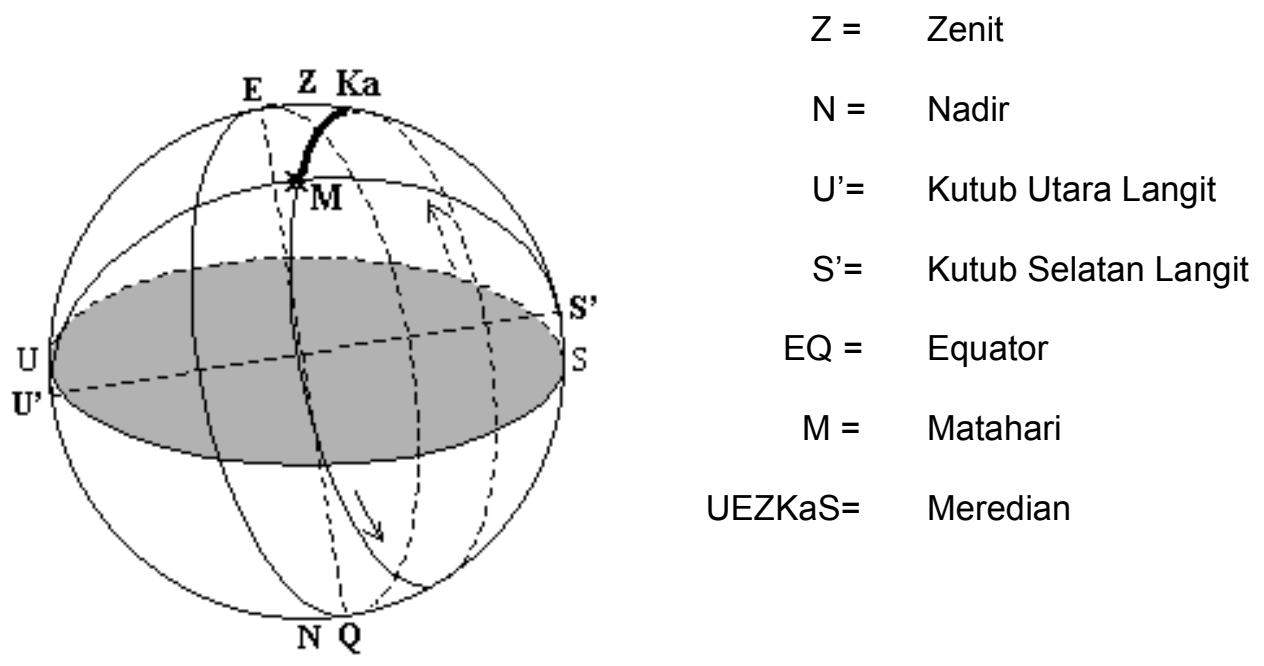

Harga atau nilai sudut waktu adalah $0^{\circ}$ sampai $180^{\circ}$. Nilai sudut waktu $0^{\circ}$ adalah ketika matahari berada di titik kulminasi atas atau tepat di meridian langit, sedangkan nilai sudut waktu $180^{\circ}$ adalah ketika matahari berada di titik kulminasi bawah.

Apabila matahari berada di sebelah barat meridian atau di belahan langit sebelah barat maka sudut waktu bertanda positif (+). Apabila matahari berada di sebelah timur meridian atau di belahan langit sebelah timur maka sudut waktu bertanda negatif (-).

Harga sudut waktu matahari ini dapat dihitung dengan rumus :

$$
\cos t_{o}=-\tan \varphi \tan \delta_{o}+\sin h_{o}: \cos \varphi: \cos \delta_{o}
$$


$\mathrm{t}_{\mathrm{o}} \quad$ = Sudut Waktu Matahari

$\varphi \quad=$ Lintang Tempat

$\delta_{0} \quad=$ Deklinasi Matahari

$\mathrm{h}_{\mathrm{o}} \quad=$ Tinggi Matahari pada awal waktu shalat

sudut waktu dinamakan positif jika benda langit yang bersangkutan berkedudukan dibelahan langit sebelah barat, dan dinamakan negative apabila benda langit berkedudukan dibelahan langit sebelah Timur. Jika benda langit sedang berkulminasi sudut waktu $=0^{\circ}$, selanjutnya besarnya diukur dengan derajat sudut dari $0^{\circ}$ sampai $180^{\circ}$, sudut waktu senantiasa berubah sebanyak $\pm 15^{\circ}$ setiap jam, hal itu disebabkan oleh gerak harian benda-benda langit yang diakibatkan oleh perputaran bumi sekeliling porosnya yang berlaku satu kali dalam setiap 24 jam. Dengan demikian, dapatlah jumlah derajat sudut waktu dipindahkan menjadi jumlah jam, menit dan detik waktu, karena :

$$
\begin{aligned}
& 360 \mathrm{o}=24 \text { jam } \\
& 150=1 \text { jam } \\
& 10 \quad=4 \text { menit } \\
& 15^{\prime} \quad=1 \text { menit } \\
& 1^{\prime} \quad=4 \text { detik, betitu selajutnya. }{ }^{9}
\end{aligned}
$$

\section{c. Ikhtiyat ${ }^{10}$}

Ikhtiyat yang diartikan dengan "pengaman", yaitu suatu langkah pengaman dalam perhitungan awal waktu shalat dengan cara menambah atau mengurangi sebesar $1 \mathrm{~s} / \mathrm{d} 2$ menit waktu dari hasil perhitungan yang sebenarnya.

Ikhtiyat ini dimaksudkan :

- agar hasil perghitungan dapat mencakup daerah-daerah sekitarnya, terutama yang berada di sebelah baratnya. @ menit $= \pm 27.5 \mathrm{~km}$

- menjadikan pembulatan pada satuan terkecil dalam menit waktu, sehingga

\footnotetext{
${ }^{9}$ Drs. Abdur Rachim, Ilmu Falak (Cet. I; Liberty; Yogjakarta:1983), h. 7

${ }^{10}$ ibid
} 
penggunaannya lebih mudah.

- untuk memberikan koreksi atas kesalahan dalam perhitungan, agar menambah keyakinan bahwa waktu shalat benar-benar sudah masuk, sehingga ibadah shalat itu benar-benar dilaksanakan dalam waktunya.

Oleh karena itu waktu zuhur adalah waktu pertengahan pada saat matahari berada di meridian (Meridian Pass) dirumuskan dengan MP = 12 - e. Sesaat setelah waktu inilah sebagai permulaan waktu dluhur menurut waktu pertengahan dan waktu ini pula lah sebagai pangkal hitungan untuk waktu-waktu shalat lainnya. ${ }^{11}$

\section{Waktu Ashar}

Menurut hadits Nabi “ nabi melakukan salat ashar pada saat panjang bayang-bayang sepanjang dirinya" dan ini dapat disimpulkan sebagai berikut :

1. Pada waktu bayang-bayang matahari sepanjang bendanya.

2. Pada waktu bayang matahari dua kali panjang bendanya

Dan secara astronomis, maka tinggi matahari pada waktu ashar dirumuskan sebagai berikut :

$$
\begin{aligned}
& \operatorname{Cotg} h=\operatorname{tg}(z m+1) \\
& \operatorname{Cotg} h=\operatorname{tg}(P-d)+1
\end{aligned}
$$

Atau dijelaskan lebih lanjut oleh Muhyiddin Khazin bahwa : ketika matahari berkulminasi atau berada di meridian (awal waktu zuhur) barang yang berdiri tegak lurus dipermukaan bumi belum tentu memiliki bayangan. Bayang itu akan terjadi manakala harga lintang tempat $(\lambda)$ dan harga deklinasi matahari $(\delta)$ itu berbeda ${ }^{12}$ seperti yang dicontohkan dalam Pada gambar berikut ini, $\mathrm{AB}$ adalah panjang tongkat yang dipancangkan di permukaan bumi. Sedangkan BAZ adalah arah zenith dan CAM adalah arah matahari ketika berkulminasi, sehingga $\mathrm{BC}$ adalah panjang bayangan tongkat ketika matahari berkulminasi yang panjangnya $\tan [\boldsymbol{\varphi}-\boldsymbol{\delta}]$.

CD panjangnya sama dengan $\mathrm{AB}$ yang nilainya 1 (satu), sehingga waktu ashar

\footnotetext{
${ }^{11} \mathrm{lbid}, \mathrm{h} .89$

${ }^{12}$ Muhyiddin Khazin, op.cit, h. 90
} 
dimulai ketika bayangan tongkat itu sepanjang BD yakni sepanjang bayangan ketika matahari berkulminasi ditambah panjang tongkat ybs atau dirumuskan dengan $\tan [\boldsymbol{\varphi}-\boldsymbol{\delta}]$ +1 .

Dengan demikian, ketika matahari pada posisi sedemikian rupa sehingga membentuk bayangan seperti itu, apabila dilihat dari permukaan bumi akan terbentuk suatu sudut yang diapit oleh arah yang menuju ke ufuk dan arah yang menuju ke matahari, yang dalam gambar di bawah ini adalah sudut D itulah tinggi matahari ketika awal waktu ashar, yang dirumuskan dengan $\operatorname{cotan} \mathbf{h}_{\text {asar }}=\tan [\boldsymbol{\varphi}-\boldsymbol{\delta}]+\mathbf{1} .^{13}$

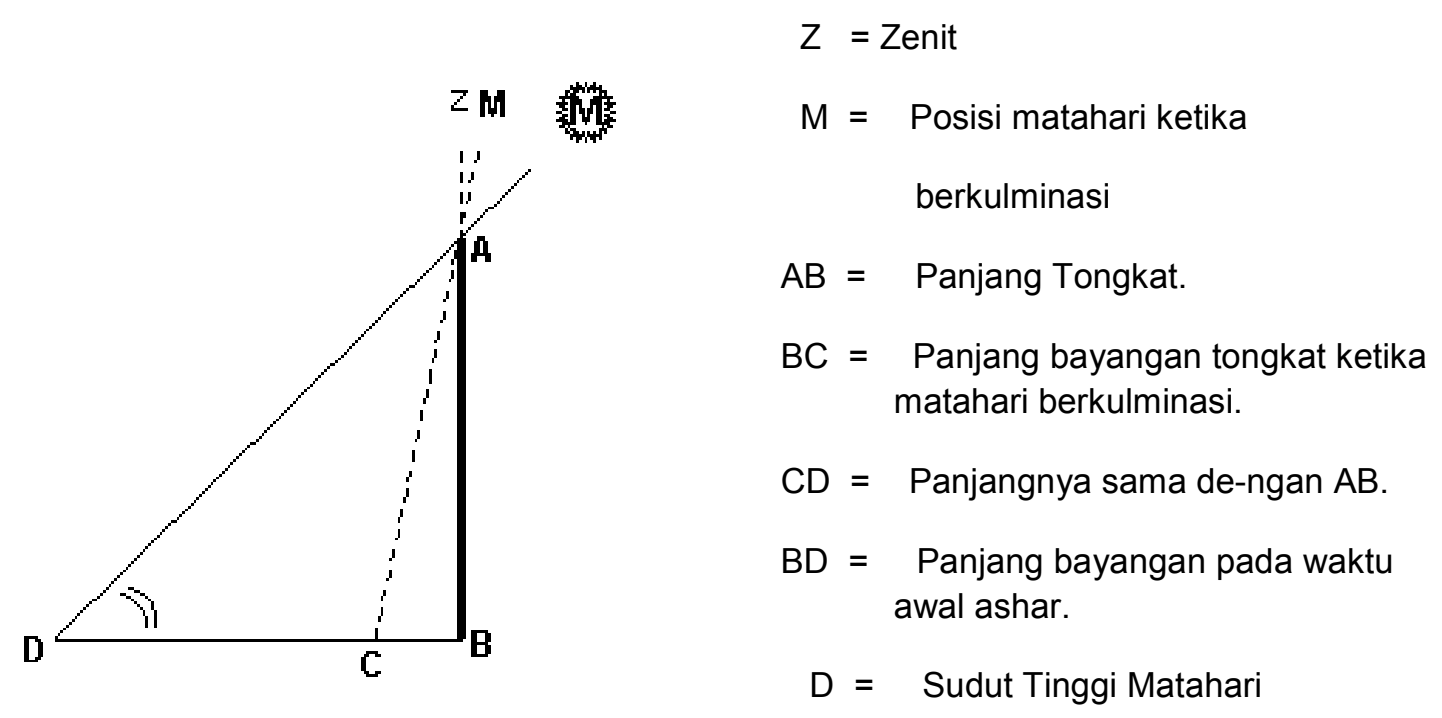

\section{Waktu Magrib}

Waktu magrib mulai pada saat setelah maahari terbenam (ghurub), dan waktu shubuh berahir pada saat matahari terbit (shuruq), dan dikatakan juga bahwa matahari terbenam, jika piringan matahari sudah seluruhnya berada di bawah ufuk (buat keadaan terbit berlaku syarat-syarat yang sama) pada waktu itu garis ufuk bersinggungan dengan tepi piringan matahari yang sebelah atas (lihat gambar) ${ }^{14}$

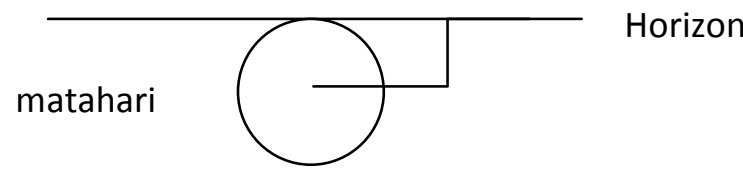

\footnotetext{
${ }^{13}$ Ibid, h. 91

${ }^{14}$ Drs. Abd. Rachim, op.cit, h. 26
} 
Penjelasannya : titik pusat matahari sudah agak jauh dibawah ufuk. Jarak dari garis ufuk ke titik pusat matahari besarnya adalah seperdua garis tengah matahari. Garis tengah matahari besarnya rata-rata 32'; jadi jarak pusat matahari dari garis ufuk besarnya $1 / 2 \times 32$ ' $=16^{\prime}$

Perhitungan tentang kedudukan maupun posisi benda-benda langit, termasuk matahari, pada mulanya adalah perhitungan kedudukan atau posisi titik pusat matahari di ukur atau dipandang dari titik pusat bumi, sehingga dalam melakukan perhitungan tentang kedudukan matahari terbenam kiranya perlu memasukkan Horizontal Parallaks matahari, kerendahan ufuk atau Dip, Refraksi cahaya, dan semidiameter matahari. Hanya saja karena parallax matahari itu terlalu kecil nilainya yakni \pm 8 sehingga palarllaks metahari dalam perhitungan waktu magrib ini dapat diabaikan. ${ }^{15}$ Atas dasar itu, kedudukan matahari atau tinggi matahari pada posisi awal waktu magrib dihitung dari ufuk sepanjang lingkaran vertical ( hmg ) dirumuskan dengan 16

$$
\begin{aligned}
& \mathrm{H}_{\mathrm{mg}}=-\left(\mathrm{SD}_{0}+\text { Refraksi }+ \text { Dip }\right) \\
& \mathrm{SD}=016^{\prime} 00^{\prime \prime} \\
& \text { Refraksi }=034^{\prime} 30^{\prime \prime} \\
& \text { Dip } \quad 0,0293 \sqrt{\text { tinggi tempat (meter) }}
\end{aligned}
$$

Perhitungan harga tinggi matahari pada awal waktu magrib dengan rumus diatas sangat dianjurkan apabila untuk perhitungan awal bulan. Tetapi apabila untuk perhitungan awal waktu salat cukup dengan $\mathrm{hmg}=-1^{0}$

\section{Waktu Isya.}

Kalau matahari sudah dibawah ufuk, cahayanya yang langsung mengenai tempat peninjauan di atas bumi, tidak ada lagi. Tetapi sinar-sinar matahari yang dipantulkan adan dibiaskan (disebarkan) masih dapat mencapai mata sipeninjau. Bila pada siang hari matahari sedang bersinar dan kita berdiri di dalam rumah, tidak ada pula cahaya matahari yang secara langsung kemata kita. Tatapi segala benda-benda di dalam rumah seperti kursi, meja, lemari dan lain-lain tampak dengan jelas oleh kita, dan di dalam rumah tetap terang kelihatannya.

\footnotetext{
${ }^{15}$ Muhyiddin khazin, op.cit, h. 92

${ }^{16}$ Ibid
} 
Cahaya matahari sampai ke dalam rumah secara dipantulkan oleh berbagai benda yang terletak di luar rumah langsung ditimpa sinar matahari. Tetapi lebih penting daripada benda-benda yang dapat kita lihat ialah berjuta-juta butir debu dan benda-benda sangat halus yang beterbangan di udara. Walaupun ukurannya amat kecil, sehingga tidak tampak oleh kita, dan cahaya yang langsung dating dari matahari kemudian dipantulkan oleh satusatu butiran itu amat sedikit, oleh jumlahnya yang begitu besar, benda-benda halus itu (pertikel-partikel) memainkan pernan yang amat penting dalam menyebarkan cahaya matahari samapi jauh ke semua sudut di dalam rumah-rumah kita. Debu-debu halus itu bolehlah dipandang sebagai suatu ni'mat Allah yang amat berharga, kena tanpa pertikel itu manusia yang hidup di atas bumi akan terpaksa pada siang hari bolong memasang penerangan di dalam rumah.

Jika partikel-partikel pada bagian yang amat tinggi diangkasa itu masih menerima sinar matahari, cahaya merah masih dapat dilihat. Bayangan merah sesudah matahari terbenam tidak kelihatan lagi jika matahari sudah $18^{0}$ dibawah ufuk, jadi jarak zenith pusat matahari sama dengan $108^{\circ}$. Pada saat itu, waktu magrib berakhir, dan masuklah waktu isya $\left(90^{0}+18^{0}=108^{0}\right)^{17}$

Dalam astronomy umum dikenal pula istilah bagi masa segera setelah matahri terbenam dan sebelum matahari terbit, yaitu : "TWILIGHT" yang dibagi kepada 3 tingkat, yaitu berturut-turut :

1. Civil twilight, Batas civil twilight ialah jika matahari $06^{0}$ dibawah horizon; pada waktu itu benda-benda di lapangan terbuka masih tampak batas-batas bentuknya; bintang-bintang yang paling terang dapat dilihat.

2. Nautical twilight, Batas nautical twilight ialah jika matahari $12^{0}$ di bawah horizon. Jika kita di laut. Ufuk hampir-hampir tidak kelihatan; semua bintang terang dapat dilihat.

3. Astronomical twilight Batas astronomical twilight ialah, bila matahari $18^{0} \mathrm{di}$ bawah ufuk; pada waktu itu gelap malam sudah sempurna (awal waktu isya). ${ }^{18}$ Awal waktu subuh, yang ditandai oleh kelihatannya fajar shadiq, dianggap masuk,

\footnotetext{
${ }^{17}$ Abd. Rachim, op.cit, h. 39

${ }^{18}$ Ibid
} 
jika matahari $20^{\circ}$ di bawah ufuk, jadi jarak zenith matahari berjumlah $110^{0} \cdot\left(90^{0}+20^{\circ}\right)$

Oleh karena itu pada posisi matahari - $18^{0}$ di bawah ufuk, malam sudah gelap karena telah hilang bias pertikel (mega merah), maka ditetapkan bahwa awal waktu isya apabila tinggi matahari $-18^{0}$. Oleh sebab itu $h_{m g}=-18^{019}$

\section{Waktu subuh.}

Untuk awal waktu subuh, Menurut hadis nabi di atas adalah pada saat mulai terbit fajar, yaitu fajar sidiq, atau awal mega merah sebelah timur mulai menyingsing.

Para ahli astronomi umum tidak membedakan kuantitas derajat antara akhir masa mega merah sebelah barat dengan awal masa mega merah sebelah timur (fajar). Mereka mengambil 180 sebagai angka patokan. Tetapi ulama islam umumnya (prof. Sa'aboedin Djambek) mengambil patokan $20^{\circ}$. Artinya, jarak zenith ke matahari pada awal waktu subuh adalah $=90^{\circ}+20^{\circ}=110^{\circ}$, sehingga tinggi matahari waktu itu $=20^{\circ}$ di bawah horizon sebelah timur. Dengan demikian awal waktu subuh $: \mathrm{h}=-20^{0} 20$

Untuk waktu terbit matahari (waktu suruq) jarak zenith matahari sama dengan pada saat magrib, yakni $=90^{0}+1^{0}=91^{0}$, maka tinggi matahari waktu suruq $=-1^{0}$, yakni $1^{0}$ di bawah horizon sebelah timur, atau $: \mathrm{h}=-1^{0}$

Terbitnya matahari ditandai dengan piringan atas matahari bersinggungan dengan ufuk sebelah timur, sehingga ketentuan- ketentuan yang berlaku untuk waktu magrib berlaku pula untuk waktu matahari terbit.

6. Waktu dhuha.

Waktu dhuha dimulai ketika matahari setinggi tombak. Dalam ilmu falak diformulasikan dengan jarak busur sepanjang lingkaran vertical dihitung dari ufuk sampai posisi maahari pada awal waktu dhuha yakni $3^{0} 30^{\prime}$ oleh karena itu digunakan hdl $=3^{0}$ 30'21, Waktu Dluha dimulai ketika ketinggian matahari sekitar satu tombak yakni 7 dziro', dalam bahasa ahli hisab kita ketinggian matahari tersebut sekitar $4^{\circ} 30^{\prime}$. Sedangkan

\footnotetext{
${ }^{19}$ Muhyiddin khazin, op.cit, h. 95

${ }^{20}$ Diktat, IImu Falak I, h. 97

${ }^{21}$ Muhyiddin Khazin, op.cit, h. 94
} 
menurut Imam Abu Hanifah ketinggian matahari sekitar dua tombak atau dalam ukuran ahli hisab $9^{\circ}$. Waktu Dluha berakhir ketika matahari tergelincir22

7. Waktu Imsak

Waktu Imsak adalah waktu tertentu sebagai batas akhir makan sahur bagi orang yang melaksanakan puasa, waktu imsak ini adalah langkah kehati-hatian agar orang yang melakukan puasa tidak melampaui batas waktu mulainya fajar. Sementara waktu yang diperlukan untuk membaca 50 ayat al-Qur'an itu sekitar 8 menit maka waktu imsak terjadi 8 menit Sebelum subuh, oleh karena itu waktu 8 menit samadengan $2^{\circ}$, maka tinggi matahari pada waktu imsak $\left(h_{i m}\right)$ ditetapkan $-22^{\circ}$ dibawah ufuk timur atau him $=-22^{\circ}$.

\section{KESIMPULAN}

Dari penentuan awal waktu salat tersebut dapat dikatakan bahwa awal waktu salat didasarkan pada peredaran semu matahari mengelilingi bumi, atau dengan kata lain waktu-waktu salat ditentukan oleh posisi matahari terhadap bumi. Maka waktu-waktu salat dapat dihitung berdasarkan kaidah ilmu falak dalam menentukan posisi matahari pada titik-titik tertentu. Atau dengan menentukan posisi matahari yang menimbulkan bayang-bayang sebagai penenda yang menunjukkan waktu-waktu salat, dan Sebelum melakukan perhitungan maka diperlukan data-data akurat sebagai data utama untuk menentukan posisi matahari yang menunjukkan waktu-waktu salat, atau dengan kata lain dengan berpedoman kepada Civil twilight, Batas civil twilight ialah jika matahari $06^{0}$ dibawah horizon; pada waktu itu benda-benda di lapangan terbuka masih tampak batasbatas bentuknya; bintang-bintang yang paling terang dapat dilihat. Nautical twilight, Batas nautical twilight ialah jika matahari $12^{0}$ di bawah horizon. Jika kita di laut. Ufuk hampir-hampir tidak kelihatan; semua bintang terang dapat dilihat. Astronomical twilight Batas astronomical twilight ialah, bila matahari $18^{0}$ di bawah ufuk; pada waktu itu gelap malam sudah sempurna (awal waktu isya).

\footnotetext{
${ }^{22}$ Ibnu Zahid Abdul Muid, Belajar ilmu Hisab, artikel.
} 


\section{DAFTAR PUSTAKA}

Al-Qur'an dan Terjemahannya

Abd. Rachim, Ilmu Falak, Cet. II; Yogjakarta: Liberty. 2004

Ilmu Falak Cet. I; Yogjakarta; Liberty:1983

Ali Parman, Ilmu Falak, Cet. I : Makassar : 2001

Artikel, Ilmu Falak I

------------Ibnu Zahid Abdul Muid, Belajar ilmu Hisab

Encip Supriatna, Hisab Rukyah dan Aplikasinya, Cet.I; PT. Refika Aditama: Bandung

Muhyiddin Khazin, Ilmu Falak dan Teori dan praktiknya, Cet. I; Yogjakarta:Buana

Pustaka, 2004 